\title{
Adding magnesium to levobupivacaine for axillary brachial plexus block in arteriovenous fistule surgery
}

\author{
Dogru K, Yildirim D, Ulgey A, Aksu R, Bicer C, Boyaci A \\ Erciyes University, Gevher Nesibe Hospital, Kayseri, Turkey. aulgey@erciyes.edu.tr
}

\begin{abstract}
Background and objectives: The aim of this study was to compare the effect of adding magnesium to levobupivacaine on sensory and motor block onset and duration for axillary brachial plexus block in chronic renal failure (CRF) patients scheduled for arteriovenous fistule surgery (AVFS).

Methods: 80 patients, ASA III, aged 30 to 70 years, randomized and divided into 4 groups: Group I $(n=20)$ received total $41 \mathrm{ml}$ of levobupivacaine $0.5 \%+1 \mathrm{ml} \mathrm{NaCl} 0.9 \%$ mixture; Group II $(\mathrm{n}=20)$ received $41 \mathrm{ml}$ of levobupivacaine $0.5 \%+1 \mathrm{ml}$ magnesium sulfate $(150 \mathrm{mg})$ mixture; Group III $(\mathrm{n}=20)$ received total $41 \mathrm{ml}$ of levobupivacaine $0.25 \%+1 \mathrm{ml} \mathrm{NaCl} 0.9 \%$ mixture; and Group IV $(\mathrm{n}=20)$ received total $41 \mathrm{ml}$ of levobupivacaine $0.25 \%+1 \mathrm{ml}$ magnesium sulfate $(150 \mathrm{mg})$ mixture by perineural axillary brachial plexus block.

All patients were evaluated with regard to motor and sensory blocks. Motor and sensory block ending times were recorded.

Results: Motor and sensory block onset times were statistically decreased in Group II when compared with Goup I, and also the motor and sensory block durations were increased in Group II when compared with Goup I ( $p<$ 0.05). Sensory block onset times were statistically decreased in Group IV when compared with Goup III $(p<0.05)$. Conclusions: We conclude that by its decreasing effect on local anesthetic dose, magnesium may reduce the side effects due to high local anesthetic doses in patients with CRF (Tab. 1, Ref. 11). Full Text in PDF www.elis.sk. Key words: magnesium, axillary brachial plexus block, levobupivacaine.
\end{abstract}

Since patients with chronic renal failure can survive with hemodialysis, the success of fistula operations bears great importance. Patients undergoing AV fistula operation usually have other clinical problems such as hypertension, coronary artery disease, heart failure, hyperkalemia, and acidosis along with CRF which puts them at high risk. In patients who undergo day surgery, the success rate of fistula formation increases as adequate blood flow is maintained as a result of the sympathetic block following regional blockade. Therefore, brachial plexus block is the most commonly preferred anesthetic method (1-3). Many adjuvant agents are used in conjunction with the anesthetic in order to achieve a prolonged effect at lower doses, prevent toxicities, begin the operation faster, and elevate the quality of anesthesia. We can mention adrenalin, calcium channel blockers (verapamil), opioids (morphine $\mathrm{HCl}$, tramadol and fentanyl), alpha-2 agonists (clonidine, dexmedetomidine), alkaline solutions and magnesium among those agents (4-7).

Magnesium is an antagonist of N-methyl-D-aspartate and calcium. Perioperatively, it has been observed to lower the required

Erciyes University, Gevher Nesibe Hospital, Kayseri, Turkey

Address for correspondence: A. Ulgey, MD, Erciyes University medical Faculty, Gevher Nesibe Hospital, Anesthesiology and Reanimation Department, 38039 Melikgazi, Kayseri, Turkey.

Fax: +90.352 .4377333$

Acknowledgement: The present study was presented at the 44th National Turkish Anesthesiology and Reanimation Congress, 27-31, October, 2010, Antalya, Turkey. dose of anesthetic when delivered intravenously, and prolong the length of anesthesia when added to the local anesthetic agent (8).

Experimental studies have shown that it inhibits the neurotransmitter release in peripheral nerves and generates the hyperpolarization possibly leading to elevated nerve block by local anesthetic agents (9).

In this study, we investigated the influence of administrating a combination of levobupivacaine plus magnesium on duration of sensory and motor block by applying brachial plexus blockade with axillary approach in patients scheduled to receive AV fistula. Our primary endpoints were the onset time and duration of motor and sensory blocks.

\section{Material and method}

Following the approval of the İnstitutional IRB, written informed consents were obtained from all the patients. Eighty patients between 30-70 years of age with ASA I-III physical status, scheduled for AV fistula surgery were enrolled in a prospective, double-blind controlled trial. The patients with weight $>120 \mathrm{~kg}$ or height $<140 \mathrm{~cm}$, neuromuscular or neurological disorder, psychiatric problem, respiratory disease, coagulation disorder, regional infection risk, history of a local anesthesia allergy, as well as those who were pregnant or at lactation, and the ones who rejected undergoing an intervention, were excluded from the study.

Routine monitoring was performed on the patients and IV lines were established. Axillary block was performed by an experienced 
Tab. 1. Sensory and motor block onset time, block durations in groups (mean \pm SD).

\begin{tabular}{|c|c|c|c|c|c|}
\hline & Group I $(n=20)$ & Group II $(n=20)$ & Gorup III $(n=20)$ & Group IV $(n=20)$ & $\mathrm{p}$ \\
\hline Onset time of sensory block (min) & $11.6 \pm 1.98$ & $9.75 \pm 1.58^{*}$ & $20.3 \pm 1.41^{*}$ & $16.2 \pm 1.1^{* \& \#}$ & $<0.05$ \\
\hline Onset time of total motor block (min) & $13.25 \pm 1.74$ & $11.5 \pm 1.5^{*}$ & $25.12 \pm 0.95^{*}$ & $23.89 \pm 1.41^{* \&}$ & $<0.05$ \\
\hline Duration of sensory block (min) & $876 \pm 46.27$ & $1023 \pm 42.31^{*}$ & $684 \pm 31.68^{*}$ & $793.5 \pm 28.33^{* \& \#}$ & $<0.05$ \\
\hline Duration of motor block (min) & $649.5 \pm 55.29$ & $793.5 \pm 74.4^{*}$ & $540 \pm 36.33^{*}$ & $598.4 \pm 32.36^{* \& \#}$ & $<0.05$ \\
\hline
\end{tabular}

Duration of motor block ( $\mathrm{min}$ )

${ }^{*} \mathrm{p}<0.05$ compaired with group I, ${ }^{\&} \mathrm{p}<0.05$ compaired with group II, ${ }^{*} \mathrm{p}<0.05$ compaired with group III

anesthesiologist with peripheral nerve stimulator by using teflonisolated $22 \mathrm{G}$ peripheral block needles of $5 \mathrm{~cm}$ in length (Stimulex cannula A, Braun melsungen AG, Germany).

Patients were randomly allocated using a sealed envelope technique. Group I $(\mathrm{n}=20)$ received $40 \mathrm{ml}(200 \mathrm{mg}) 0.5 \%$ levobupivacaine (Chirocaine vial $0.5 \% 10 \mathrm{ml}$ injectable solution, Abbott, USA) plus $1 \mathrm{ml} 0.9 \% \mathrm{NaCl}$; Group II $(\mathrm{n}=20)$ received $40 \mathrm{ml}$ (200 mg) $0.5 \%$ levobupivacaine plus $1 \mathrm{ml}$ (150 mg) magnesium sulfate; Group III $(\mathrm{n}=20)$ received $40 \mathrm{ml}(100 \mathrm{mg}) 0.25$ $\%$ levobupivacaine (Chirocaine vial $10 \mathrm{ml} 0.25 \%$ injectable solution, Abbott, USA) plus $1 \mathrm{ml} 0.9 \% \mathrm{NaCl}$; and Group IV ( $\mathrm{n}=20)$ received $40 \mathrm{ml}(100 \mathrm{mg}) 0.25 \%$ levobupivacaine plus $1 \mathrm{ml}(150$ $\mathrm{mg}$ ) magnesium sulfate.

Systolic, diastolic, and mean arterial values of pressure as well as heart rate were recorded at baseline after 5, 10, 15, 30, 45, 60, $75,90,105$, and 120 minutes.

Each nerve was examined for sensory and motor blockade every two minutes during the first 30 minutes after the injection, and at the beginning and end of the operation. Following the achievement of complete sensory and motor block, surgery was started. In cases where analgesia proved to be inadequate, 50-100 $\mu \mathrm{g}$ fentanyl was intravenously administered.

Sensory block was assessed for each cutaneous innervation area by pinprick test in 3 categories ( 0 : presence of pain; 1 : no pain but presence of tactile sense [partial block = analgesia]; and 2: no pain at all).

Motor block level was assessed in three categories and the results were noted $(0$ : the muscle pertaining to the nerve under examination shows no sign of block; 1 : the muscle pertaining to the nerve under examination shows signs of partial block; 2: the muscle pertaining to the nerve under examination shows signs of complete block). The cases were monitored until the end of sensory and motor block. The time when patients were able to perform ankle flexion and extension, was assumed as the end of motor block.

Moreover, the patients who develop thrombosis or vasospasm within 24 hours of fistula surgery were planned to be noted.

The compliance of demographic variables such as body weight, height, age, and length of operation with normal distribution, was analyzed with Kolmogorov-Smirnov test while the observed values were found to exhibit a normal distribution $(p>0.05)$.

Quantitative parametric data obtained from the groups were presented as mean \pm standard deviation. One-way ANOVA was used for evaluation of the data. In presence of significance, Scheffe method, a posthoc test, was employed. Chi-square test was used for analysis of the qualitative values. $p<0.05$ was recognized as statistically significant.

\section{Results}

There was no statistically significant difference between the groups with regard to demographic data (age, height, and body weight), length of operation, and gender of patients.

Following the documentation of baseline values and completion of the injections, no statistically significant difference was found between the groups with regard to HR values after 5, 10, $15,30,45,60,75,90,105,120$ minutes $(p>0.05)$. Similarly, no statistically significant difference was observed between the groups in MAP values after 5, 10, 15, 30, 45, 60, 75, 90, 105, 120 minutes $(\mathrm{p}>0.05)$.

All patients in the study demonstrated a complete sensory block. All patients in groups I and II demonstrated a complete motor block. In Group III, 4 patients exhibited a partial motor block and 16 patients showed a complete motor block. In Group IV, one patient demonstrated a partial motor block and 19 patients showed a complete motor block

As compared with Group I, Group II demonstrated a statistically significant shortening in time to complete the sensory and motor block, while showing a significant prolongation in total duration of sensory and motor block (Tab. 1) $(\mathrm{p}<0.05)$.

When compared with Group I, Group III and Group IV showed a statistically significant prolongation in time to complete the sensory and motor block, while exhibiting a statistically significant shortening in total duration of sensory and motor block (Tab. 1) $(\mathrm{p}<0.05)$.

As compared with Group III, Group IV displayed a statistically significant shortening in time to complete the sensory block ( $\mathrm{p}<$ 0.05 ), however there was no statistically significant shortening in time to complete the motor block ( $p>0.05$ ). As compared with Group III, Group IV showed a statistically significant prolonging in total duration of sensory and motor block (Tab. 1) $(\mathrm{p}<0.05)$. As compared with Group II, Group IV exhibited a statistically significant prolonging in time to complete the sensory and motor block (Tab. 1) $(\mathrm{p}<0.05)$. As compared with Group II, Group IV showed a statistically significant shortening in total duration of sensory and motor block (Tab. 1$)(p<0.05)$. None of the cases demonstrated postoperative thrombi and vasospasm.

\section{Discussion}

In this study, we showed that the addition of magnesium to levobupivacaine for axillary brachial plexus block in AV fistula surgery performed through the forearm of CRF patients shortened the onset times of sensory and motor block and prolonged the total durations of sensory and motor block. 
Esmaoglu et al (4) added dexmedetomidine to levobupivacaine in their axillary block procedures and observed a shorter onset of block along with prolonged duration of block and postoperative analgesia. Nevertheless, they also reported bradycardia resulting from addition of dexmedetomidine in $23 \%$ of the cases. Xavier et al (5) showed that addition of clonidine to bupivacaine in brachial plexus block did not prolong the length of postoperative analgesia; however, they reported a decrease in mean arterial pressure and heart rate.

Gunduz et al.(10) performed axillary block by adding 100 and $150 \mathrm{mg}$ magnesium to prilocaine along with using intravenous application of magnesium, and they reported that perineural magnesium prolonged sensory and motor block as compared with the control and intravenous magnesium groups.

Investigators who add dexamethasone to lidocaine in axillary brachial plexus block report a prolonged duration of sensory and motor block (6). Robaux et al added $50 \mathrm{mg}, 100 \mathrm{mg}$, and 200 mg tramadol to $1.5 \%$ mepivacaine and reported that tramadol prolonged the duration of block in a dose-dependent way while causing tolerable complications such as nausea, vomiting and increased sedation (7).

Magnesium has been shown to potentiate the anesthetic effect in peripheral applications of local anesthetics $(8,9)$. Magnesium increases the influences of anesthetic and analgesic agents and enables them to induce their expected effects at lower doses.

Intrathecal magnesium $(50 \mathrm{mg})$ delivery has been shown to prolong the fentanyl analgesia without inflicting any neurotoxic complications among 52 pregnant women who were under analgesia for childbirth (11). Magnesium is believed to show this effect by natural calcium block and NMDA antagonism. In our study, the addition of magnesium $(150 \mathrm{mg})$ to levobupivacaine did not produce any side effects over hemodynamic parameters of the patients, which is a significant advantage in cases with compromised and unstable intravascular volume. Prolonged analgesia during postoperative period decreases the need for additional analgesics which in turn reduces the complications associated with those drugs in CRF patients. The achievement of effective anesthesia and postoperative analgesia by half the dose of local anesthetics by means of magnesium addition is an important advantage in clinical practices involving CRF patients.

In conclusion, an addition of $150 \mathrm{mg}$ perineural magnesium to levobupivacaine in axillary brachial plexus block was observed to reduce the onset times of sensory and motor block and prolong the durations of sensory and motor block. Therefore, we believe that magnesium allows reducing the local anesthetic concentration and dose without causing loss of any block properties and thus it may be an advantageous clinical practice in AV fistula surgery.

\section{References}

1. Adnan T, Elif A, Ayse K, Gülnaz A. Clonidine as an adjuvant for lidocaine in axillary brachial plexus block in patients with chronic renal failure. Acta Anaesth Scand 2005; 19: 563-568.

2. Altıntas F, Gümüs F, Kaya G, Mihmanli I, Kantarci F, Kaynak K, Cansever S. Interscalene brachial plexus block with bupivakaine and ropivacaine in patients with chronic renal failure: Diaphragmatic excursion and pulmonary function changes. Anesth Analg 2005; 100: 1166-1171.

3. Martin R, Beauregard L, Tetrault JP. Brachial plexus blockade and renal failure. Anesthesiology 1988; 69: 405-406.

4. Esmaoglu A, Yegenoglu F, Akin A, Turk CY. Dexmedetomidine added to levobupivakaine proplongs axillery brachial plexus . Anesth Analg 2010; 111: 1548-1551.

5. Xavier C, Van Gessel E, Hoffmeyer P, Gamulin Z. Clonidine combined with a long acting local anesthetic does not prolong postoperative analgesia after brachial plexus block but does induce hemodynamic changes. Anesth Analg 2001; 92: 199-204.

6. Movafegh A, Razazian M, Hajimaohammadi F, Meysamie A. Dexamethasone added to lidocaine prolongs axillary brachial plexus blockade. Anesth Analg 2006; 102: 263-267.

7. Robaux S, Blunt C, Viel E, Cuvillon P, Nouguier P, Dautel G, Boileau S, Girard F, Bouaziz H. Tramadol added to $1.5 \%$ mepivakaine for axillery brachial plexus block improves postoperative analgesia dose-dependently. Anesth Analg 2004; 98: 1172-1177.

8. Koinig H, Wallner T, Marhofer P. Magnesium sulfate reduces intra- and postoperative analgesic requirements. Anesth Analg 1998; 87: 206-210.

9. Akutagawa T, Kitahata L, Saito H, Collins J, Katz J. Magnesium enhances local anesthetic nerve block of frog sciatic nerve. Anesth Analg 1984; 63: 111-116.

10. Gündüz A, Bilir A, Güler S, Güleç S. Magnesium added to prilocaine prolongs the duration of axillery plexus block. Reg Anesth Pain Med 2006; 31: 233-236.

11. Buvanendran A, Mc Charty R, Kroin C. Intrathecal magnesium prolongs fentanyl analgesia: A prospective randomized controlled trial. Anesth Analg 1984; 63: 661-666. 